\title{
MARINE TRAFFIC ON MEDITERRANEAN SEAS AND ITS DIVISIONS
}

\author{
Ana-Maria CHIROȘCĂ, Liliana RUSU \\ "Dunărea de Jos" University of Galati, Faculty of Engineering, Department Mechanical Engineering \\ 111 Domnească Street, RO-800201, Galati, Romania \\ * Corresponding author: ana.chirosca@ugalro
}

\begin{abstract}
The Mediterranean Sea is the largest sea in the world and its most important sub-divisions regarding maritime traffic are the Ionian Sea, Tyrrhenian Sea, Ligurian Sea, Balearic Sea, Alboran Sea, Aegean Sea and the Adriatic Sea.

This paper analyses how marine traffic has evolved in this area over the centuries, considering the historical traffic corridors (such as the Adriatic-Ionian Transport Corridor), the climate, the different sea-level rise due to climate change, and the wave heights and its period.

Water circulation on Mediterranean is affected on a short time scale due to weather changes, and especially due to changes in salinity and temperature that could make the sea more stratified by the end of the 21 st cen-tury.

Regarding the complex meteorological factors, the high number of islands, islets, narrow passages, canals and submerged rocks in the waters, Mediterranean Sea remains one of the most important shipping routes with significant tanker traffic and unfortunately one of the areas with higher risk of maritime accidents, 75\% of the shipping accidents being recorded in Aegean Sea.
\end{abstract}

Keywords: Mediterranean Sea, marine traffic, types of ships, navigation, wave heights, wave period

\section{INTRODUCTION}

The Mediterranean Sea (Fig. 1) is the largest sea in the world, having a length of over $3,800 \mathrm{~km}$. The sea is delimitated by Central Europe, Western Asia, and North Africa. All over the centuries, the Mediterranean Sea was a historical route, where many events have taken place.

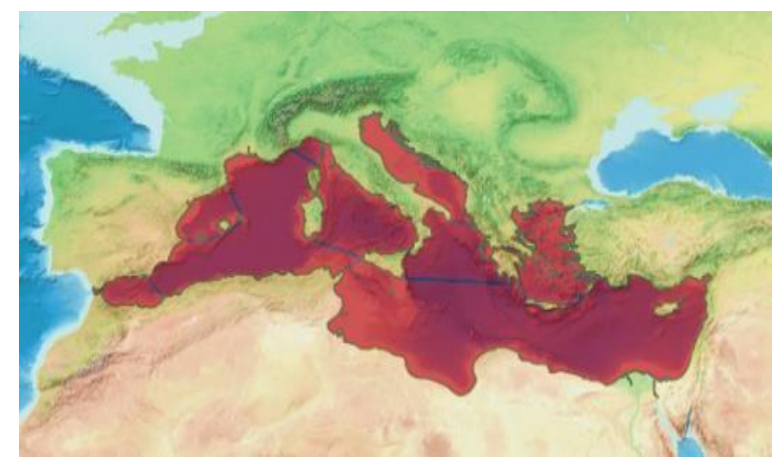

Fig. 1. Mediterranean Sea [1]
Its waters bathe the three peninsulas of Europe (Iberian, Italian and Balkan), communicate with the Atlantic through the Strait of Gibraltar, with the Black Sea through the Bosphorus and the Dardanelles and with the Red Sea through the Suez Channel.

The Mediterranean Sea is in the subtropical zone and has a special Mediterranean climate: mild winters and dry summers. The general level of pollution in the Mediterranean Sea is high. The largest amount of pollutants enters the Mediterranean Sea from the coast, especially in areas with high production development and tourism. A serious source of pollution of the marine environment is the flow of over 70 rivers that transport waste on the territories of river basins and a significant contribution to coastal pollution is made by offshore oil production.

The length and width of the Mediterranean Sea are not indicated exactly (see Table 1 ), because the basin is constantly changing its limits and it is almost impossible to calculate the exact values. 
Table 1. Main particulars of the Mediterranean Sea

\begin{tabular}{|c|c|}
\hline Length $[\mathrm{km}]$ & 3860 \\
\hline Width $[\mathrm{km}]$ & 800 \\
\hline Depth $[\mathrm{m}]$ & 5267 \\
\hline Total surface $\left[\mathrm{km}^{2}\right]$ & 2500000 \\
\hline Water Volume $\left[\mathrm{km}^{3}\right]$ & 3750000 \\
\hline Level of salinity $[\%]$ & 3.8 \\
\hline
\end{tabular}

\section{MEDITERRANEAN SEAS AND ITS DIVISIONS}

The Mediterranean Sea has the following main subdivisions: Ionian Sea, Tyrrhenian Sea, Ligurian Sea, Balearic Sea, Alboran Sea, Aegean Sea, Cretan Sea and Adriatic Sea.

Ionian Sea (Fig. 2) has an increased flow of traffic due to the passengers and the various types of ships that carry goods through this network. Also, many ferries cross this area. The Ionian Sea is bounded by the Aegean Sea through the Gulf of Corinth and the Corinth Channel.

The Tyrrhenian Sea (Fig. 3) is one of the most beautiful and attractive tourist areas in Europe. The mountain chains, sunny resorts, and active volcanoes bring more people each year. It is located on the border between Eurasian and African tectonic plates and therefore plays an important role in international trade. The Sea is also a large fishing industry.

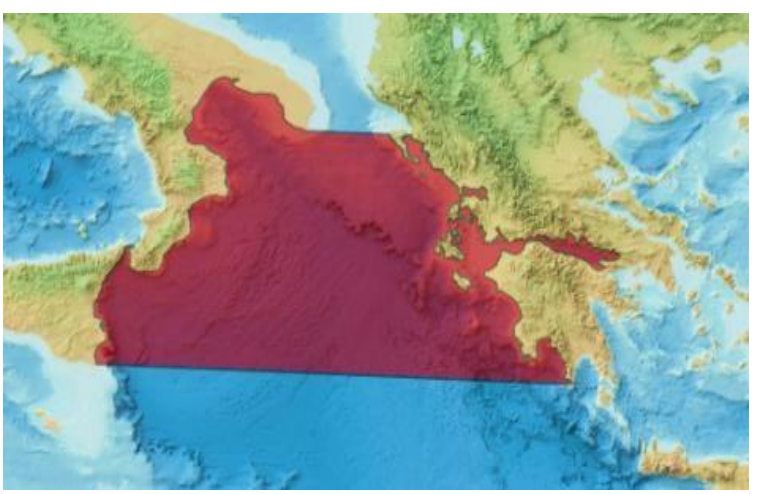

Fig. 2. Ionian Sea [1]

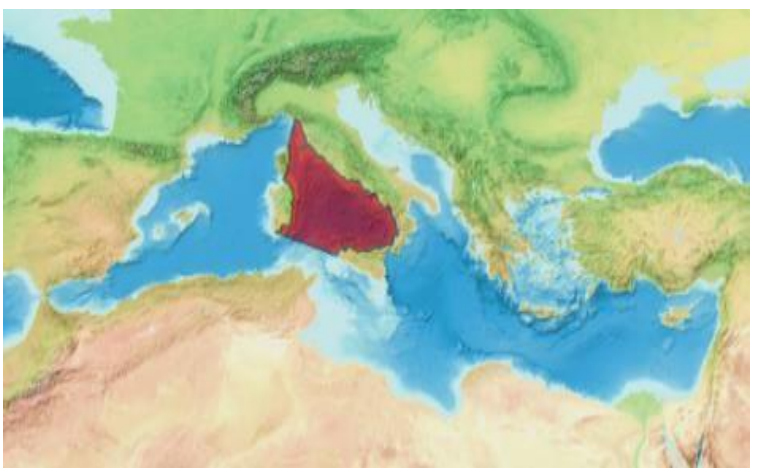

Fig. 3. Tyrrhenian Sea [1]
The Ligurian Sea (Fig. 4), between Corsica and Tuscany, it is also known for its beauty and its touristic potential. The Balearic Sea (Fig. 5), also named Iberian Sea, has a great coastline and has the most popular sailing areas on the Mediterranean Sea. Lots of important ports are here, among them, Barcelona, Marseille and Valencia.

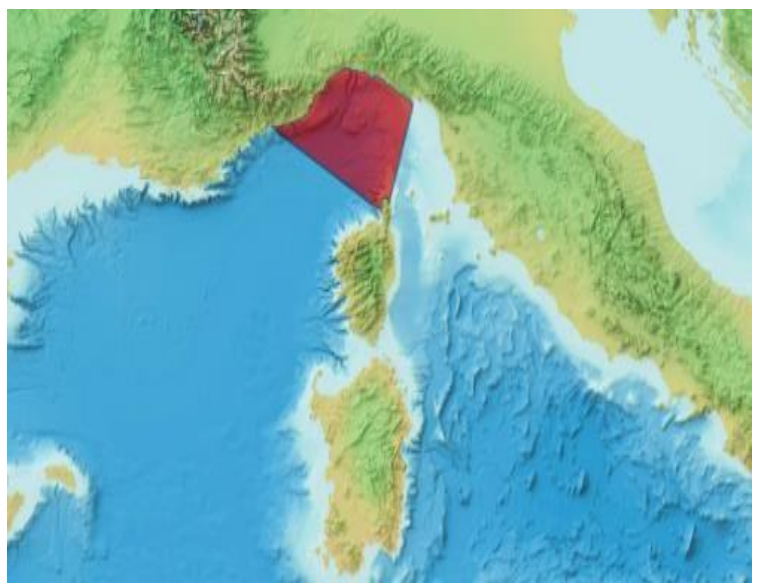

Fig. 4. Ligurian Sea [1]

The Alboran Sea (Fig. 6) is a transition zone between the ocean and the sea. All cargo vessels entering the Mediterranean Sea must pass through the Strait of Gibraltar and the Alboran Sea before disembarking in the ports.

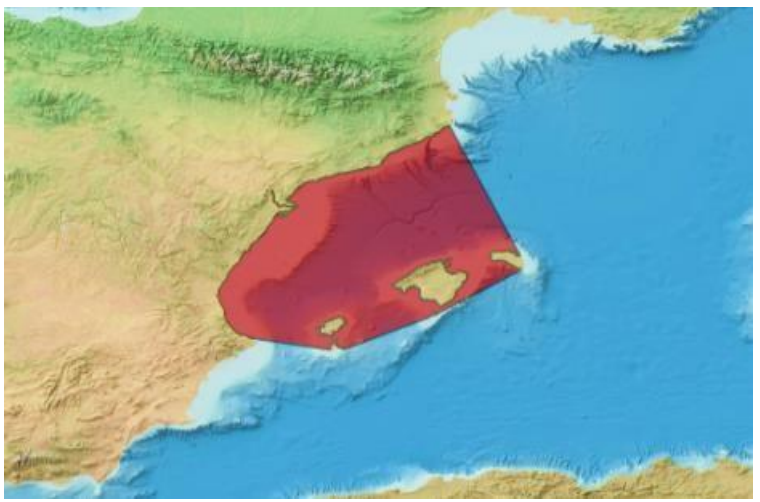

Fig. 5. Balearic Sea [1]

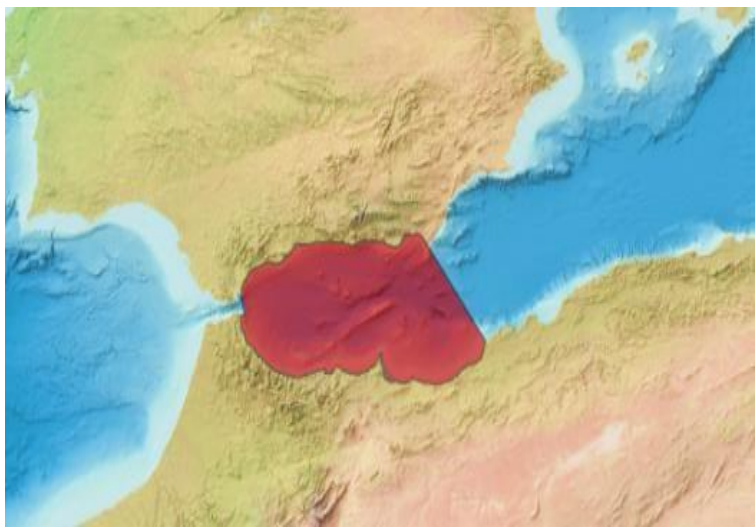

Fig. 6. Alboran Sea [1] 
The Aegean Sea (Fig. 7) is connected to the Marmara Sea and the Black Sea by the straits of the Dardanelles and Bosphorus.

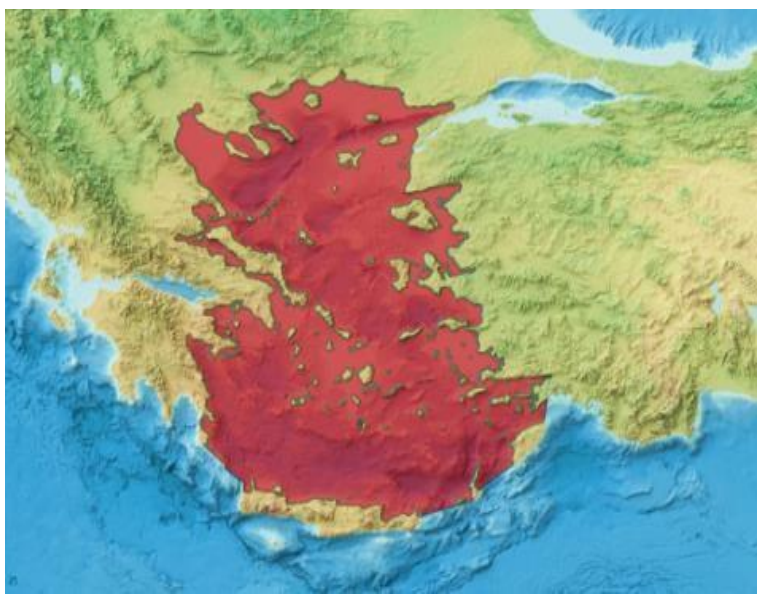

Fig. 7. Aegean Sea [1]

The Adriatic Sea (Figure 8) separates the Italian Peninsula from the Balkan Peninsula. Shipping and tourism are also quite important for the Adriatic Sea. In this area, more than one million tons of goods are managed per year.

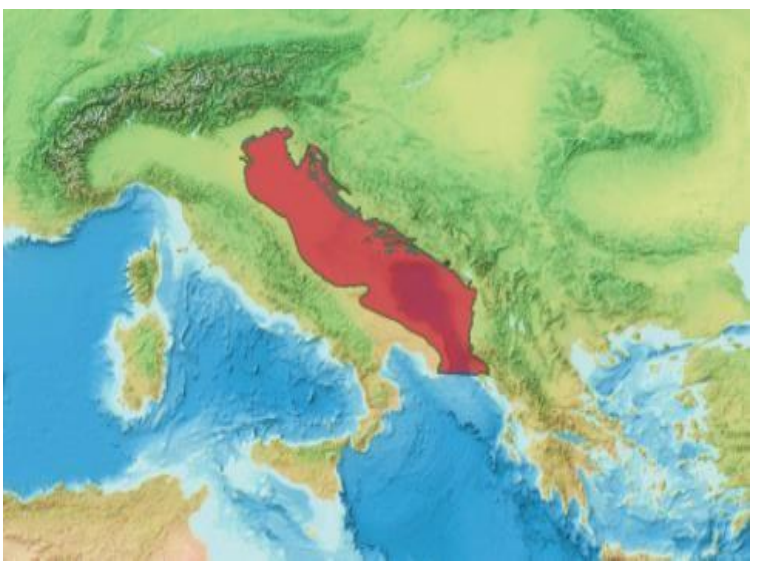

Fig. 8. Adriatic Sea [1]

\section{WAVE CLIMATE AND WATER CIRCULATION CHARACTERISTICS}

The Mediterranean Sea [4] is experiencing several climate changes due to the short residence time of the waters. The circulation of water is described by the waters that enter from the Atlantic Ocean through the Strait of Gibraltar.

In the Aegean Sea, surface water flows counterclockwise due to factors such as regional climate, freshwater discharges from rivers and seasonal variations in surface water in the Black Sea through the Dardanelles Strait.

The Adriatic Sea is characterized by a cyclonic surface circulation. Moreover, the northern sector of the Adriatic Sea has a wide shelf with a depth of less than $50 \mathrm{~m}$ being a site of dense water formation.
According to climate projections, the Mediterranean Sea could become warmer and the salinity of the water will be higher.

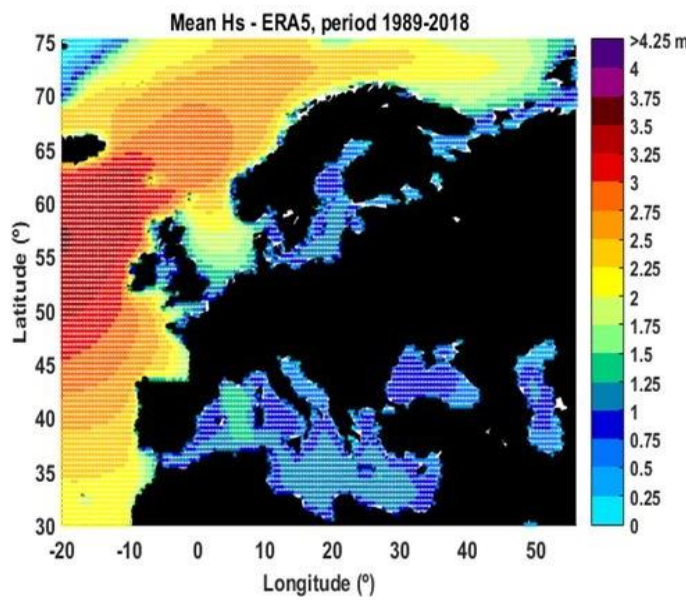

Fig. 9. The spatial distribution of the mean wave heights

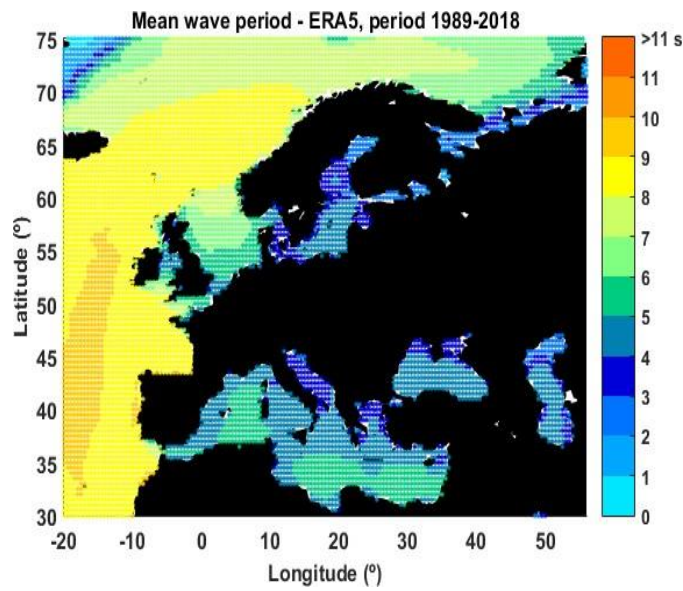

Fig. 10. The spatial distribution of the mean wave periods

Figures 9 and 10 present the means of the significant wave height (Hs) and the mean wave period (Tm) calculated for the period 1989-2018, based on the information provided by ERA5, the latest reanalysis database developed by ECMWF (European Center for Medium-Range Weather Forecasts). It can be observed that the highest values of $\mathrm{Hs}$ means are found in the western part of the basin (around $1.7 \mathrm{~m}$ ) while in the case of Tm these are located in western and southern areas (around $6 \mathrm{~s}$ ).

\section{MARINE TRAFFIC}

The Mediterranean Sea has popular shipping routes and represents around one-third of the world's total merchant shipping [3]. The Western Mediterranean is known as the shipping corridor for many European countries.

In Figure 11 we can see the marine traffic and density map extracted from marine traffic at the be- 
ginning of this year. These types of figures were extracted for each sub-division. (Fig. 12 to Fig. 18).

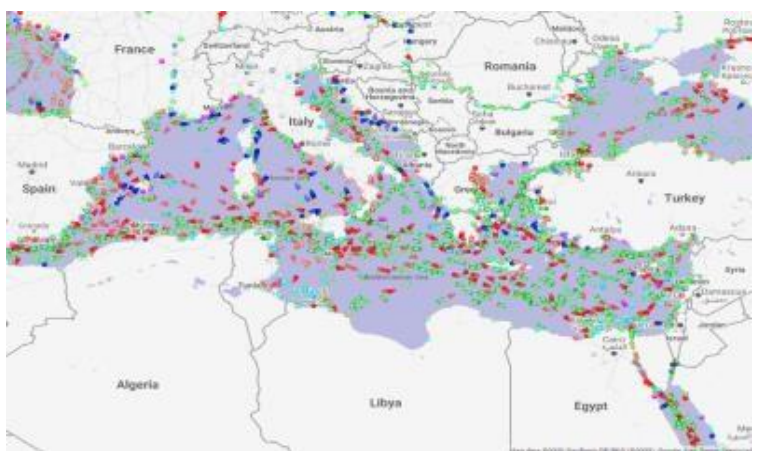

a)

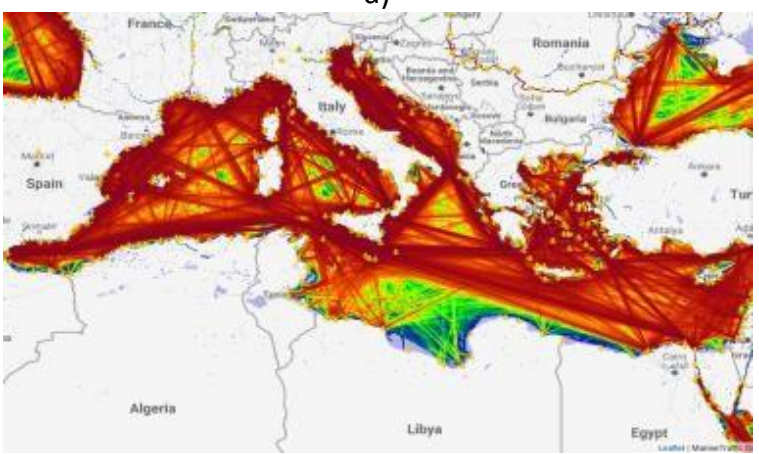

b)

Fig. 11. Marine Traffic (a) and Marine Traffic Density Map (b) in the Mediterranean Sea [2]

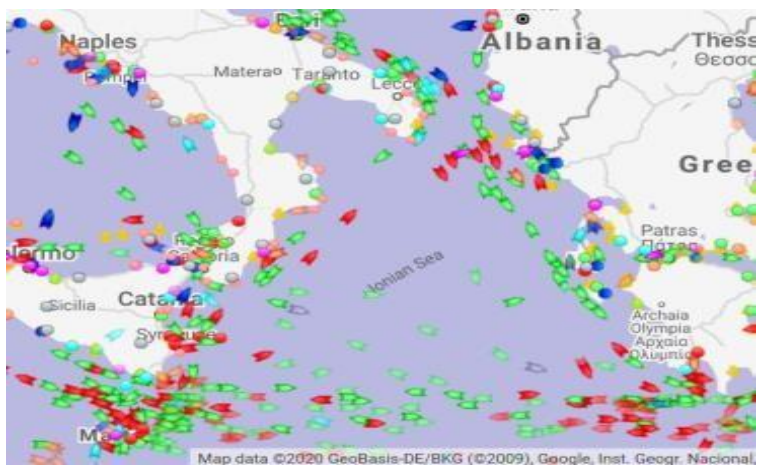

a)

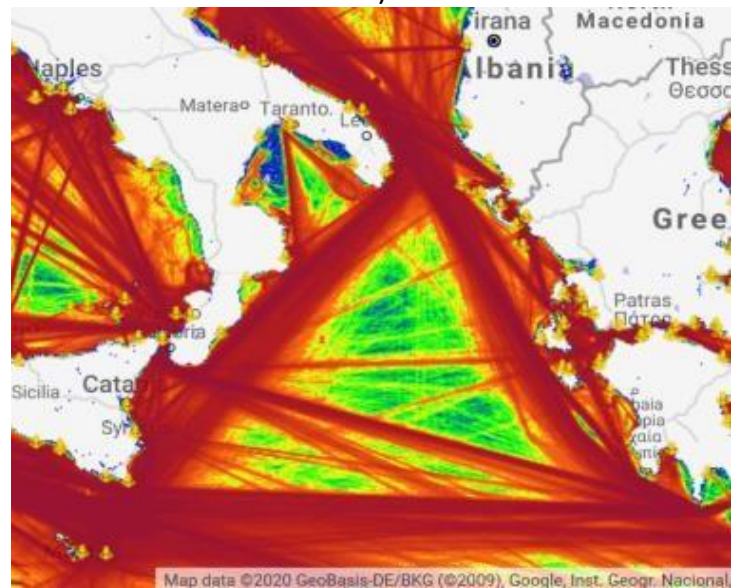

b)

Fig. 12. Marine Traffic (a) and Marine Traffic

Density Map (b) in the Ionian Sea [2]
The Adriatic-Ionic Transport Corridor is a historic traffic corridor that connects the Adriatic coast and the Ionian coast. To navigate the Adriatic Sea you need a good knowledge of hydro-navigational and hydro-meteorological conditions, especially in summer.
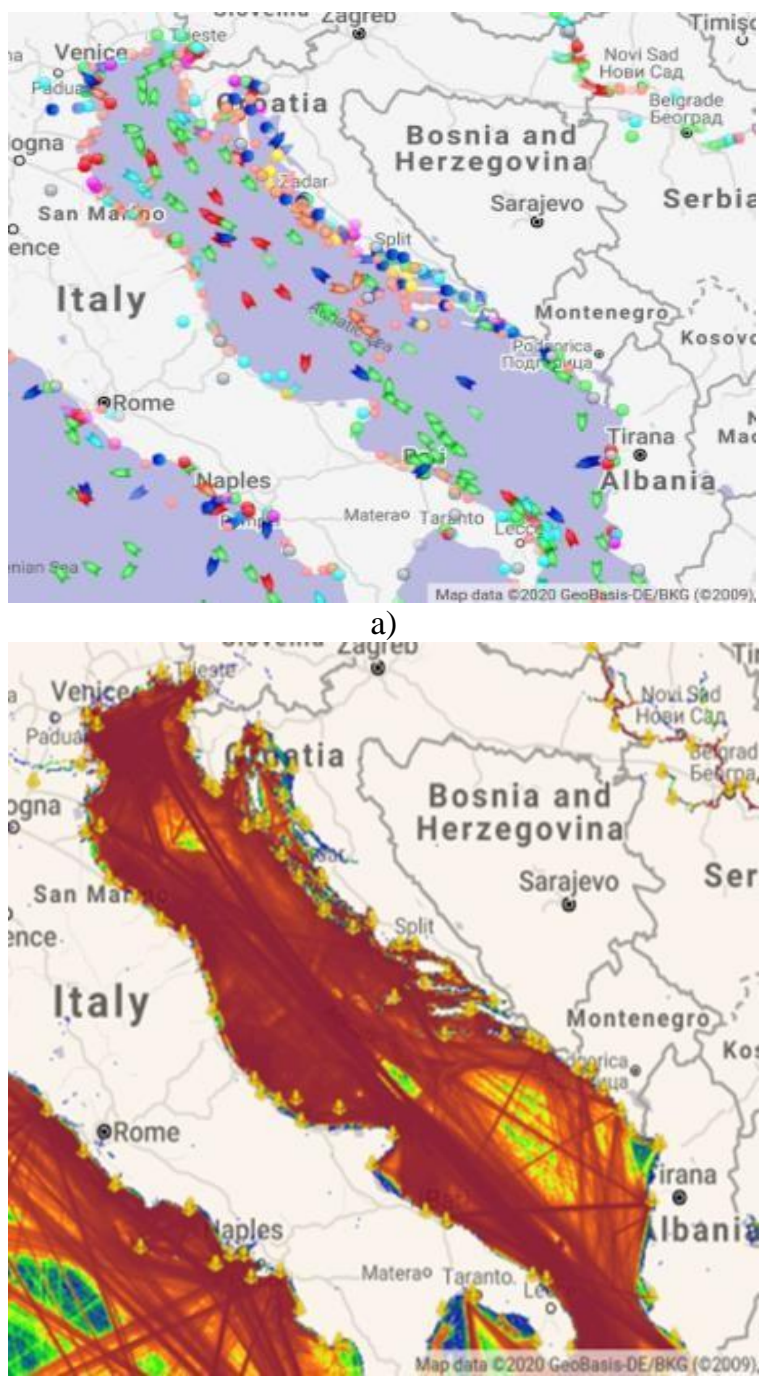

(b)

Fig. 13. Marine Traffic (a) and Marine Traffic Density Map (b) in the Adriatic Sea [2]

In the Ionian Sea we can find several ferry routes.

The Tyrrhenian Sea has a developed infrastructure for navigation and is easy to navigate for novice crews.

The Balearic Sea is used as a transition zone between the Alboran Basin and the Liguro-Provençal.

Since ancient times, sailing through the Aegean Sea has been the most widely used mode of travel, as navigation was easier than travelling through the land of the Greek mainland and the coastal areas of Anatolia. As a result, the Mediterranean Sea is at high risk for major spills caused by tankers [5], [6]. 


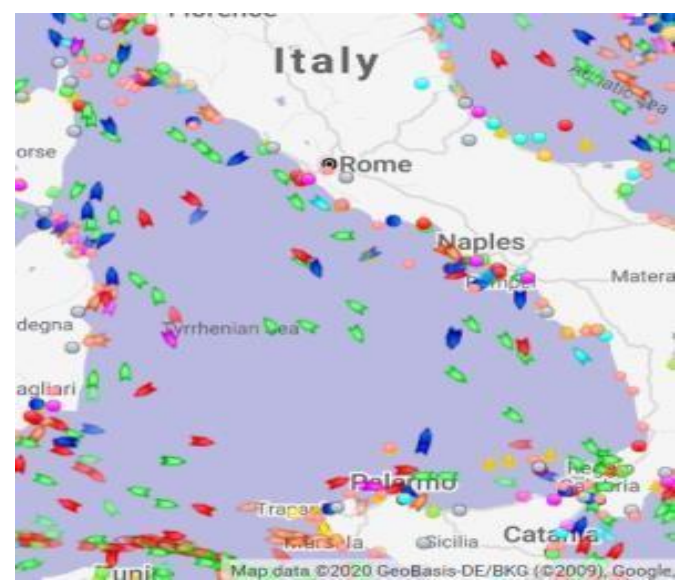

a)

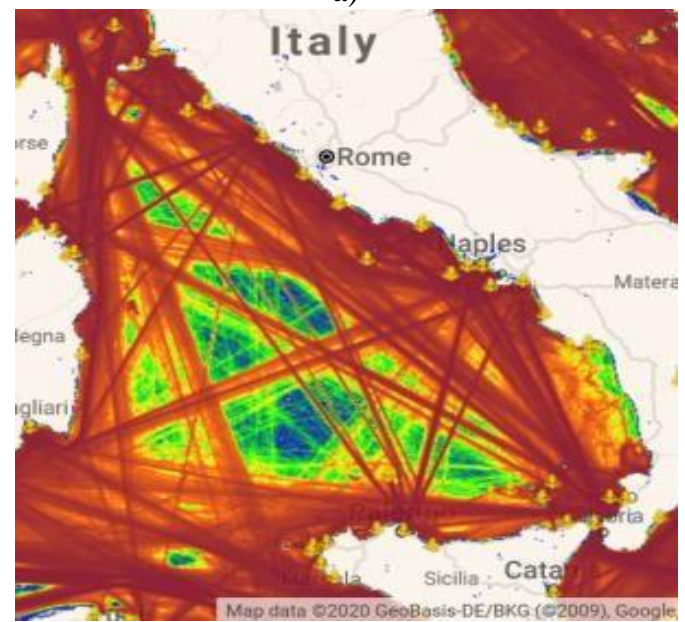

b)

Fig. 14. Marine Traffic (a) and Marine Traffic Density Map (b) in the Tyrrhenian Sea [2]

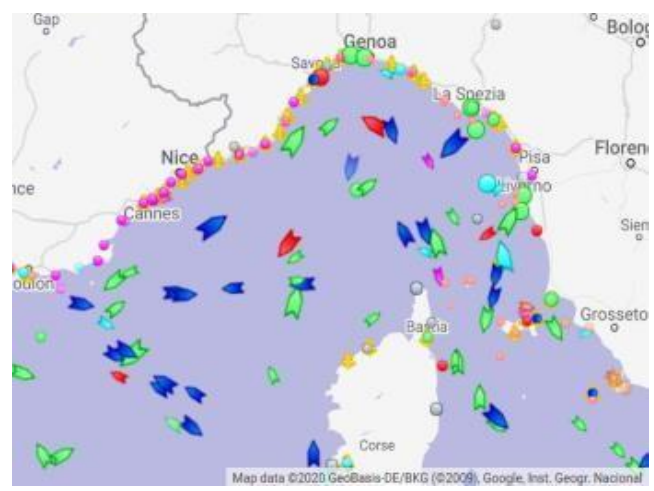

a)

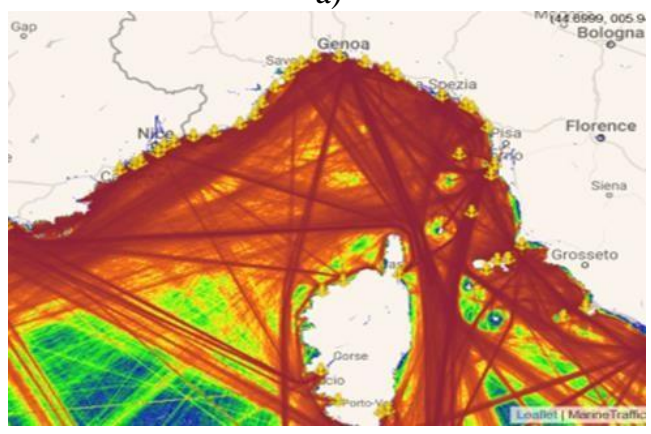

b)

Fig. 15. Marine Traffic (a) and Marine Traffic Density Map (b) in the Ligurian Sea [2]

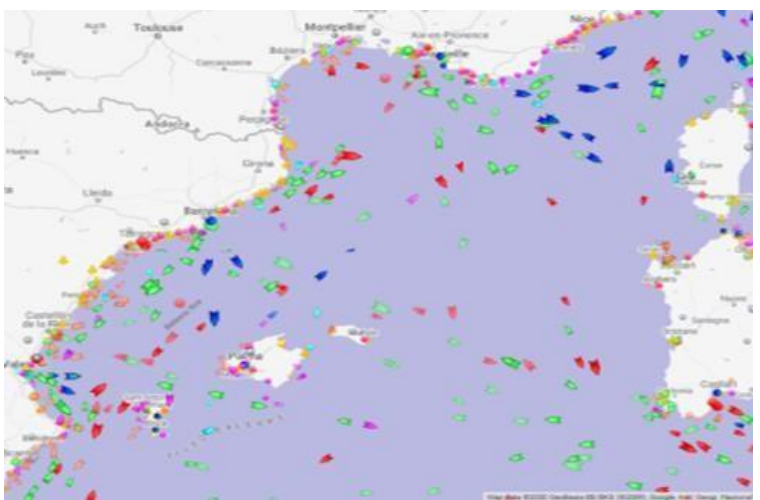

a)

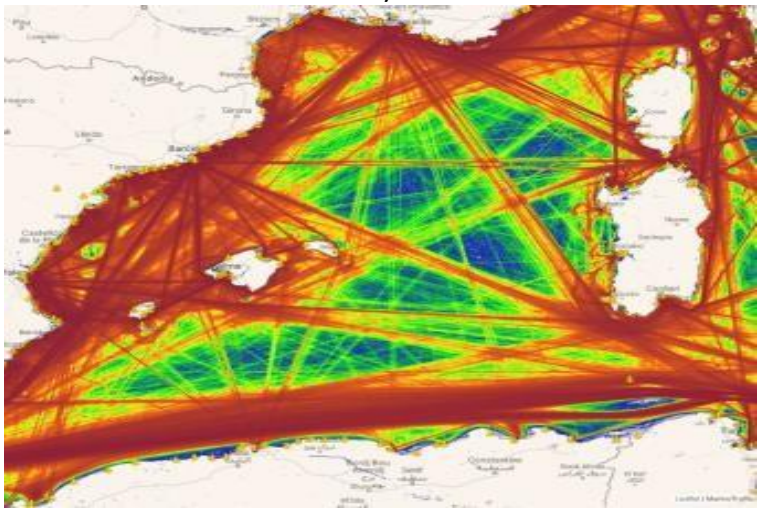

b)

Fig. 16. Marine Traffic and Marine Traffic Density Map - Balearic Sea [2]

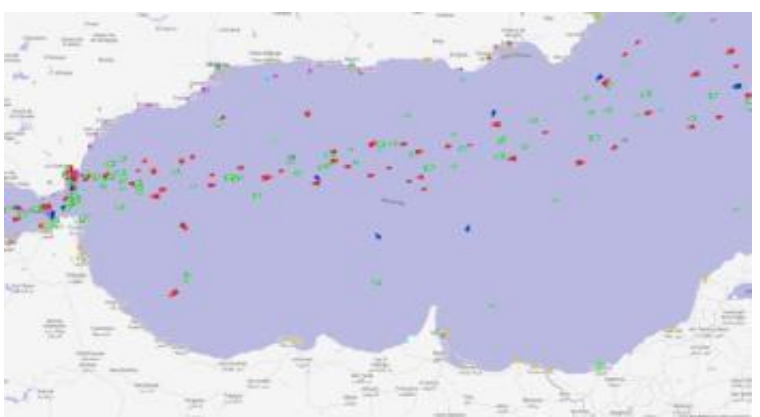

a)

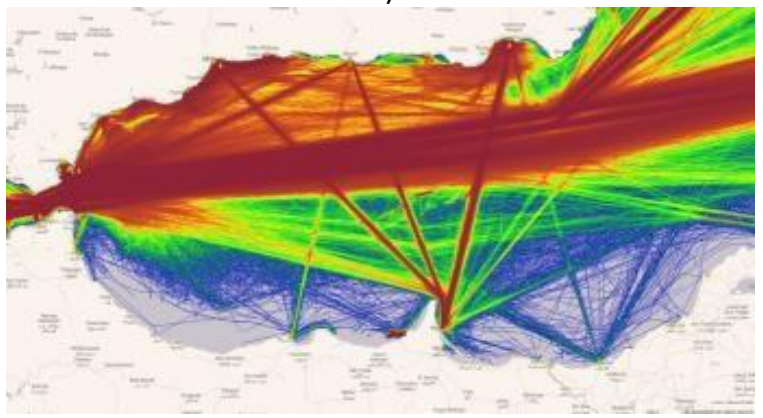

b)

Fig. 17. Marine Traffic (a) and Marine Traffic Density Map (b) in the Alboran Sea [2] 


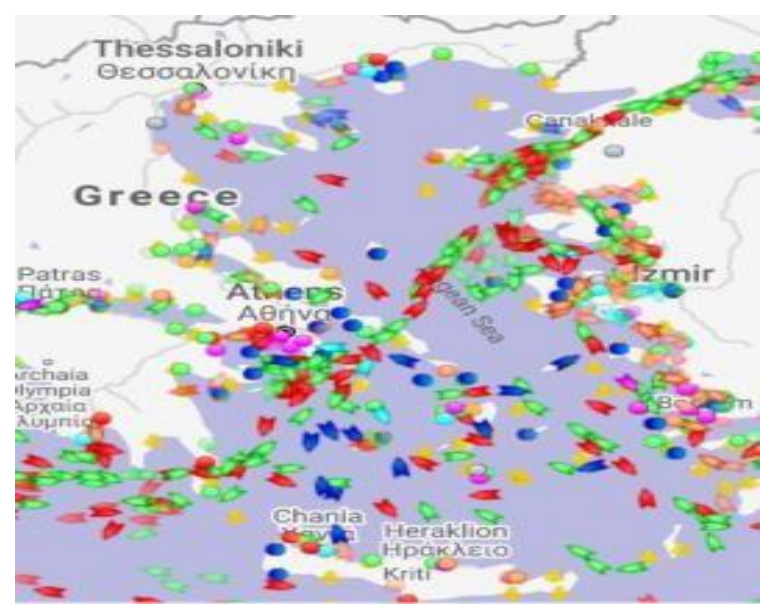

a)

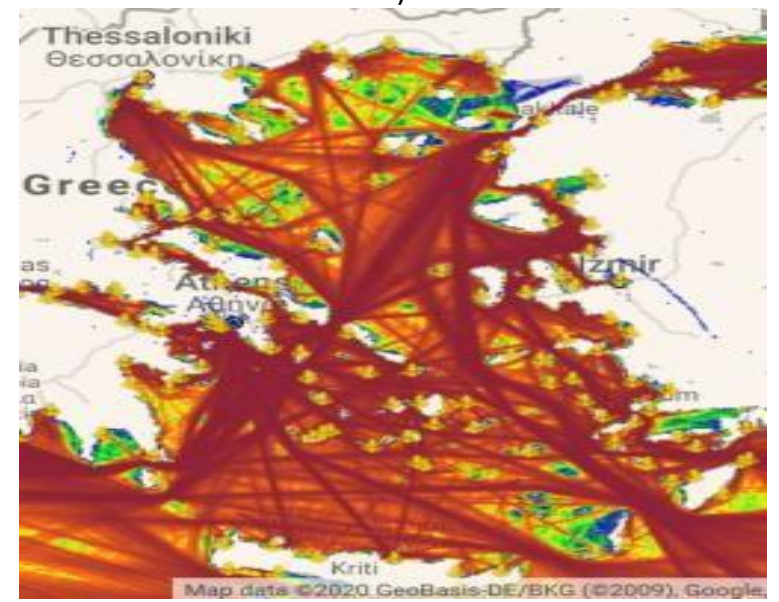

b)

Fig. 18. Marine Traffic (a) and Marine Traffic Density Map (b) in the Aegean Sea [2]

The main shipping areas in the Aegean Sea, between Greece and Turkey, where there is significant tanker traffic, are considered an area with a high risk of a maritime accident because most accidents have occurred in this area. Other factors that lead to accidents are difficult navigation due to the large number of islands, islets and rocks submerged in water and many complex meteorological elements.

The Mediterranean Sea favors shorter water transport due to the high density of ports, and thus maritime transport is shorter compared to road freight transport. However, shipping will also become more expensive due to the imposed maritime regulations.

\section{TYPES OF SHIPS}

Almost every type of ships can be found in this area. Main types of ship: cargo tanks, tankers, passenger ships, high-speed craft, yachts and military ships.

The Mediterranean Sea is crossed by thousands of tankers [5], sailing on major routes in the Middle East, at sea to ports in Europe and North America, through the Suez Canal. These waters are crossed by a multitude of fishing vessels. Greece has the largest fishing fleet in Europe.
Among the ports that are located along the entire Greek and Turkish coast of the Aegean Sea, Piraeus is the main port in Greece being the largest passenger port in Europe and the third largest in the world. It is also one of the largest container traffic ports in Europe.

Shipping is also important for the Baltic Sea. There are many ports in this region, most of them connect international routes and provides commercial and passenger traffic throughout the year. Dynamics of the maritime transport sector is in a continuously changing, mainly influenced by transport demand, which has a close relationship with economic growth in the region.

In the Baltic Sea, we find three main types of ships: ferries and passenger ships, cargo vessels and containers. Over $50 \%$ of ships are cargo ships. Container transport seems to be the most used and complex of all. It is generally divided into two groups: sea carriers and ocean carriers. The capacity of ships is increasing as the old ships are replaced with new and larger ones.

In the last two decades, due to cheap commercial flights and high-speed rail connections, there has been a downward trend in maritime passenger transport. On the other hand, the cruise ship sector is due to an upward trend, with Europe being one of the key markets for the global cruise ship industry.

\section{CONCLUDING REMARKS}

In this study, the marine traffic on the Mediterranean sea and its divisions were investigated.

The Mediterranean is the largest sea in the world and its most important sub-divisions regarding maritime traffic are the Ionian Sea, Tyrrhenian Sea, Ligurian Sea, Balearic Sea, Alboran Sea, Aegean Sea and the Adriatic Sea. The Mediterranean Sea is and will be a sea of passage and a sea of land powers.

Shipping activity is determined by many different factors, but the most important are the characteristics of the ship and the evolution of technology. Regarding the characteristics of the ship, the main trend is the quantitative and qualitative development of the fleet. The existing fleet is changing, globally, into a smaller number of ships, but with newer and larger ships.

Larger ships achieve better efficiency and lower unit costs, but this trend also has a huge impact on ports around the world. For larger ships, there is a smaller list of ports that can still provide marine traffic.

Another important factor is the changing types of ships that make up the world's maritime fleet.

The fastest growing types are container vessels. These days, container vessels are constantly growing and carrying cargo that is being traded carefully on a large scale.

In conclusion, maritime transport in the Mediterranean is likely to increase both on an intra-European 
and extra-European scale due to global population growth, economic growth and the effects of increasing globalization.

In the future, it is expected that there will be a larger number of ships that will allow more efficient and economical freight transport.

\section{REFERENCES}

[1] *** IHO 23-3rd: Limits of Oceans and Seas, Special Publication 23, 3rd Edition 1953, published by the International Hydrographic Organization, http://www.marineregions.org/, accessed on February 2020

[2] *** Map data@2020 GeoBasis-DE/BKG (@2019), Google, Inst. Geogr. Nacional, https://www.marinetraffic.com, accessed on February 2020

[3] *** The EU in the world - transport,

https://ec.europa.eu/eurostat/statistics-explained/, accessed on 21.05.2020
[4] Hernanz P., Racault M., Font-Munoz J., Basterretxea G. (2018), Trends in phytoplankton phenology in the Mediterranean Sea based on ocean color remote sensing, October 2018 Remote Sensing of Environment 221 (September 2018):50-64

[5] *** Study of Maritime Traffic Flows in the Mediterranean Sea - Final Report - Unrestricted Version, July 2018, "Euromed Cooperation on Maritime Safety and Prevention of Pollution from Ships - SAFEMED" (MED 2005/109-573) being implemented by the Regional Marine Pollution Emergency Response Centre for the Mediterranean Sea (REMPEC)

[6] Abdulla A., Linden O. (2008) Maritime traffic effects on bi-odiversity in the Mediterranean Sea: Review of impacts, priority areas and mitigation measures. Malaga, Spain: IUCN Centre for Mediterranean Cooperation. 